\title{
PENDIDIKAN DAMAI (PEACE EDUCATION) BAGI ANAK-ANAK KORBAN KONFLIK
}

\author{
Sukendar \\ Flinder University of South Australia \\ e-mail: sukendar@yahoo.co.id
}

\begin{abstract}
The conflict is as natural of law (sunnatullah) that always there in the course of human life. So that conflicts do not lead to violence and social disaster, the conflicts need to be managed properly. Managing conflicts is not solely aimed at the cessation of conflict, or the signing of a peace agreement between the parties to the dispute. Over, conflict management must be followed by the management of post-conflict conditions. Among the efforts the condition of post-conflict is recovery of the affected populations, especially children who are the most vulnerable groups in a conflict. One remedy is to educate children affected by conflict through peace education. This needs to be done so that they are free from the trauma, did not carry a grudge in life, and capable of being a man who loves peace. This study will explore the efforts of peace education for children affected by conflict in the Latansa Islamic Boarding School, Cangkring, Karanganyar, Demak.
\end{abstract}

\begin{abstract}
$* * *$
Konflik merupakan sesuatu yang alami yang selalu ada dalam kehidupan manusia. Oleh karena itu agar konflik tidak mengakibatkan kekerasan dan petaka sosial maka konflik perlu dikelola dengan tepat. Mengelola konflik tidak sematamata ditujukan bagi penghentian konflik atau penandatanganan kesepakatan antara kelompok-kelompok yang bertikai. Lebih dari itu, manajemen konflik harus diikuti dengan manajemen post-konflik. Di antara berbagai upaya manajemen post-konflik adalah pemulihan terhadap orang-orang yang menjadi korban konflik, khususnya anak-anak yang memang rentan terhadap efek konflik. Salah satu penanganannya adalah melalui pendidikan agar mereka terbebas dari perasaan traumatik, tidak membawa kedukaan mereka, serta mampu menjadi orang yang mencintai perdamaian. Kajian ini akan melihat bagaimana upaya pendidikan damai yang dilakukan oleh Pondok Pesantren Latansa Cangkring Karanganyar Demak.
\end{abstract}

Keywords: pendidikan damai, korban, konflik 


\section{A. Pendahuluan}

Sejarah bangsa Indonesia menunjukan bahwa konflik merupakan kenyataan yang sulit dihindari. Beberapa sosiolog menyatakan bahwa konflik merupakan realitas yang ada dan bisa dijumpai dalam kehidupan sehari-hari. Konflik ini bisa terjadi dalam relasi interpersonal maupun dalam kehidupan komunal, dan muncul sebagai dampak dari interaksi sosial. Konflik-konflik yang terjadi di Indonesia, baik yang berbasis etnis, agama maupun politik telah diupayakan penyelesaiannya oleh pemerintah maupun masyarakat melalui perangkat hukum yang menyangkut ranah hukum dan melalui kearifan lokal yang dimiliki bangsa Indonesia seperti tradisi pela gandong dan baku bae dalam konflik di Maluku. ${ }^{1}$

Namun, perlu dicatat bahwa penanganan konflik tidaklah hanya sebatas pada berhentinya konflik, atau ditandatanganinya perjanjian perdamaian antara pihak-pihak yang bersengketa. Lebih dari itu harus ada pengelolaan kondisi pasca konflik, berupa upaya untuk menghidupkan kembali fungsi pranata-pranata sosial yang mandul akibat konflik. Pengelolaan kondisi pasca konflik inilah yang disebut oleh Eugenia Date-Bah sebagai "jobs after war".2 Di antara upaya pengelolaan kondisi tersebut adalah pemulihan kondisi para korban konflik, terutama perempuan dan anak-anak yang merupakan kelompok rentan (vulnerable groups) dalam sebuah konflik.

Penanganan anak korban konflik dengan bantuan kemanusiaan, berupa layanan kesehatan untuk merehabilitasi luka-luka fisik serta bantuan logistik memang perlu dilakukan. Namun itu semua diperlukan hanya untuk jangka pendek. Pertolongan yang paling dibutuhkan adalah bagaimana pemerintah dan masyarakat mampu membawa anak-anak itu keluar dari sejarah kelam yang baru mereka lalui, dan membuat mereka belajar bahwa kekerasan adalah sesuatu yang harus dihindari. Sehingga tidak ada lagi benih-benih peperangan dan kekerasan di masa yang akan datang yang mengancam keutuhan bangsa ini. ${ }^{3}$

1 Ichsan Malik, "Kedamaian, Keadilan, Hak Asasi \& Penegakan Hukum," bahan presentasi kuliah Pasca Sarjana IAIN Walisongo, Semarang, 27-28 Maret, 2008.

2 Bah-Date, Euginia, Jobs After War: A Critical Challenge in the Peace and Reconstruction Puzzle, (Geneva: International Labour Office, 2003).

3 Nizar, M., "Memadamkan Dendam Anak-anak Korban Konflik di Aceh," artikel online: http://www.kabarindonesia.com/berita.php?pil=20\&dn=20080925144603, 25 September 2008, diakses 28 September 2010. 
Untuk itu penelitian ini akan memfokuskan pembahasannya pada pendidikan anak pasca konflik, pendidikan yang akan membantu mereka untuk menjadi individu-individu yang terbebas dari dendam, mampu bersikap toleran, mencintai perdamaian dan menghindari kekerasan, yaitu pendidikan damai atau peace education.

Dipilihnya anak-anak korban konflik sebagai fokus penelitian ini dikarenakan beberapa pertimbangan. Pertama, dalam suatu konflik anak-anak seringkali menjadi pihak yang paling lemah dan paling tidak diuntungkan. Kedua, trauma yang diderita anak-anak akibat dari menyaksikan kekerasan yang terjadi di depan mereka akan berakibat buruk jika tidak disembuhkan. Ketiga, tanpa adanya pendidikan yang baik anak-anak korban konflik akan cenderung memiliki justifikasi untuk melakukan tindakan balas dendam atas apa yang terjadi kepada diri mereka atau keluarga mereka sehingga berpotensi menimbulkan konflik yang berkesinambungan. Keempat, dari sisi kehidupan beragama, anak-anak korban konflik yang tidak memiliki kesadaran toleransi antar umat beragama akan menjadi aktor-aktor konflik agama di masa-masa yang akan datang.

Sudah ada upaya penanganan anak-anak korban konflik, termasuk munculnya Undang-Undang No. 20 tahun 2003 tentang Sistem Pendidikan Nasional, khususnya pasal 32 yang mengatur tentang pendidikan khusus dan pendidikan layanan khusus. Upaya ini dilakukan agar anak-anak yang bermasalah, khususnya korban konflik bisa hidup normal sebagaimana anakanak yang lain, dan mampu menjadi aktor-aktor pembangunan bangsa yang bermanfaat dalam bingkai kebinekaan Indonesia. Upaya ini tentunya perlu didukung oleh lembaga-lembaga pendidikan yang dimiliki pemerintah, maupun lembaga-lembaga pendidikan swadaya masyarakat seperti pondok pesantren.

Salah satu lembaga pendidikan yang menangani anak-anak korban konflik, yang juga akan menjadi sasaran dari penelitian ini, adalah Pondok Pesantren Modern Latansa. Pondok pesantren ini menampung anak-anak korban konflik di Indonesia bagian Timur, khususnya Maluku dan Papua, baik konflik komunal maupun konflik individual (seperti korban konflik keluarga). Dipilihnya Pondok Pesantren Modern Latansa, karena fakta bahwa pondok ini memiliki komitmen yang kuat untuk turut mendidik anak-anak korban konflik sebagaimana diberitakan dalam Harian Suara Merdeka, 1 Maret 2010, 
dan diliput serta disiarkan oleh Televisi Republik Indonesia (TVRI) Jawa Tengah pada tanggal 7 Desember 2010. Di samping itu, pondok pesantren ini menunjukan trend kemajuan dari tahun ke tahun, dan bahkan menjadi salah satu dari sedikit pondok pesantren yang memiliki program Pendidikan Layanan Khusus (PLK) bagi anak-anak yang bermasalah.

\section{B. Pendidikan Damai}

Pengertian pendidikan damai, secara sederhana, dapatlah dipahami dari pendapat Tricia S. Jones, sebagaimana dikutip Ahmad Baedowi, yang mendefinisikan pendidikan damai atau pendidikan resolusi konflik sebagai " $a$ spectrum of processes that utilize communication skills and creative and analytic thinking to prevent, manage, and peacefully resolve conflict".4

Untuk lebih memahami makna pendidikan damai dalam pengertian Boulding di atas, maka ada baiknya jika istilah tersebut di-breakdown kata-perkata, yaitu kata 'pendidikan' dan 'damai'. Dua kata tersebut adalah konsep yang perlu dipahami untuk mengerti apa itu pendidikan damai. Dari pemahaman terhadap kedua konsep tersebut akan muncul sebuah konsep yang merupakan perpaduan dari konsep 'pendidikan' dan 'damai', yaitu Pendidikan Damai.

Pendidikan adalah suatu proses atau perbuatan yang khusus diperlakukan oleh manusia sesuai dengan kodrat yang dikaruniakan tuhan kepada manusia. Makhluk yang lain nampaknya tidak memerlukan perbuatan ataupun tindakan yang disebut pendidikan. Tuhan telah menciptakan manusia dalam bentuk bayi, makhluk tiada daya, berhadapan dengan manusia yang telah dewasa. Pendidikan merupakan usaha untuk menjembatani manusia yang memiliki kemampuan-kemampuan yang diperlukan untuk melangsungkan tugas hidupnya. Menurut Ngalim Purwanto adalah segala usaha orang dewasa dalam pergaulannya dengan anak-anak untuk memimpin perkembangan jasmani dan rohaninya ke arah kedewasaan. ${ }^{5}$ Menurut Ahmad D. Marimba, pendidikan adalah bimbingan atau pimpinan secara sadar oleh si pendidik terhadap perkembangan jasmani dan rohani si terdidik menuju terbentuknya kepribadian yang utama. ${ }^{6}$

${ }^{4}$ Ahmad Baedowi, "Pendidikan Damai dan Resolusi Konflik untuk Sekolah," Media Indonesia, Senin, 1 Maret 2010.

5 Ngalim Purwanto, Ilmu Pendidikan Teoritis dan Praktis, (Bandung: Remaja Rosdakarya, 1995), h. 10.

${ }^{6}$ Ahmad. D. Marimba, Pengantar Filsafat Pendidikan Islam, (Bandung: al-Ma'arif, 1989), h. 23. 
Dalam Undang-Undang No. 20 Tahun 2003 tentang Sistem Pendidikan Nasional, pendidikan adalah usaha sadar untuk mewujudkan suasana belajar dan proses pembelajaran agar peserta didik secara aktif mengembangkan potensi dirinya untuk memiliki kekuatan spiritual keagamaan, pengendalian diri, kepribadian, kecerdasan, akhlak mulia, serta keterampilannya yang diperlukan dirinya, masyarakat bangsa dan negara. ${ }^{7}$

Dari beberapa pengertian menurut beberapa pakar pendidikan, maka penulis berinisiatif menyimpulkan, bahwa pendidikan adalah segala usaha yang dilakukan baik untuk dirinya sendiri ataupun orang lain guna menuju kesempurnaan sehingga mau dan mampu melaksanakan norma-norma kebenaran dan kebaikan.

Sedangkan makna damai, sebagai kata inti dari kedamaian, menurut Ichsan Malik dapat didefinisikan sebagai dihormatinya manusia dan kemanusiaan secara optimal akibat bekerjanya sistem sosial, ekonomi, politik, keamanan, dan pertahanan secara efektif, yang berujung kepada terwujudnya keadilan kepada semua pihak. Definisi ini bersifat menyeluruh, untuk membedakannya dengan damai yang cukup diartikan sebagai berakhirnya perang yang terjadi, atau berhentinya konflik kekerasan. ${ }^{8}$

Reardon menegaskan bahwa damai adalah ketiadaan kekerasan dalam berbagai bentuk, apakah itu bentuk fisik, sosial, psikologis, maupun struktural. Bagi O'Kane pengertian Reardon adalah pengertian yang menyederhanakan masalah, terlalu pasif dan tidak responsif terhadap cara bagaimana berdamai dengan masa lalu. Damai dalam pengertian di atas juga dapat berpotensi menyebabkan pengabaian terhadap perasaan ketidakpercayaan dan kecurigaan yang dimiliki oleh orang-orang yang terlibat dalam konflik. ${ }^{9}$

Menurut Johan Galtung damai memiliki dua wajah. Pertama, damai yang negatif. Damai yang negatif adalah ketidakadaan perang atau kondisi tanpa konflik langsung (absent of conflict). ${ }^{10}$ Kondisi tanpa konflik ini bukanlah kondisi yang tercipta dengan sendirinya, namun membutuhkan prasyarat-

7 UU No. 20 Tahun 2003 tentang Sistem Pendidikan Nasional, pasal 1 ayat 1.

8 Ichsan Malik, “Kedamaian, Keadilan, Hak Asasi \& Penegakan Hukum”.

${ }^{9}$ Ibid.

10 Johan Galtung "A Mini Theory of Peace," January 4, 2007, artikel online: http:// www.transnationalorg/Resources_Treasures/2007/Galtung_MiniTheoryhtml, diunduh tanggal 5 November 2010.

Walisongo, Volume 19, Nomor 2, November 2011 
prasyarat agar konflik tidak terjadi, yaitu tidak adanya sebab-sebab yang mendorong terjadinya konflik. ${ }^{11}$

Damai negatif, disamping membutuhkan prasyarat tidak adanya sebabsebab konflik, juga membutuhkan kontrol kekerasan yang dilakukan oleh pemerintah melalui pengamanan dan perlindungan. Strateginya adalah melalui pemisahan, sehingga pihak-pihak yang berkonflik tidak bertemu satu dengan lain. Model ini dapat dilakukan dalam situasi konflik baru terjadi, tetapi untuk jangka waktu lama sebaiknya tidak dilakukan.

Wajah kedua dari perdamaian, menurut Galtung adalah damai positif (positive peace). Damai yang positif adalah suasana dimana terdapat kesejahteraan, kebebasan, dan keadilan. Sebabnya, damai hanya dapat terjadi jika terdapat kesejahteraan, kebebasan, dan keadilan di dalam masyarakat. Tanpa itu tidak akan pernah terjadi kedamaian yang sesungguhnya di dalam masyarakat. ${ }^{12}$

Selain tipe damai negatif dan damai positif menurut Galtung, juga terdapat damai dingin (cold peace) dan damai panas (hot peace). Dalam damai dingin terdapat sedikit rasa kebencian diantara pihak-pihak yang bertikai tetapi juga kurangnya interaksi menguntungkan antarpihak yang dapat membangun kepercayaan, salingketergantungan, dan kerjasama. Bagi damai panas, kerjasama aktif diperlukan untuk menjadi jembatan untuk memperbaiki masa lalu dan membangun masa depan. Hal ini membutuhkan titik temu (common ground) dan perhatian bersama terhadap masalah-masalah kemanusiaan yang dialami. Masalah-masalah kemanusiaan tersebut dapat berupa kemiskinan, hak asasi manusia, keterbelakangan pendidikan, persoalan kesehatan, diskriminasi, ketidakadilan, polusi tanah, air dan udara.

Gabriel Solomon, sebagaimana dikutip oleh H.B. Danesh menyimpulkan bahwa aktivitas pendidikan damai saat ini berada dalam empat kategori: (1) pendidikan damai semata-mata sebagai 'aktivitas perubahan mindset'; (2) pendidikan damai semata-mata sebagai 'penanaman seperangkat kecakapan atau skill'; (3) pendidikan damai sebagai 'promosi hak asasi manusia (khususnya di negara-negara dunia ketiga)', dan (4) pendidikan damai sebagai

11 Tentang teori-teori penyebab konflik, lihat Simon Fisher et.al., Mengelola Konflik Keterampilan dan Strategi untuk Bertindak, terj. SN. Karikasari, dkk., (Jakarta: Gramedia, 2001).

12 Johan Galtung, "A Mini Theory of Peace”. 
aktivitas pengelolaan lingkungan hidup, pelucutan senjata dan promosi budaya damai. ${ }^{13}$

Di antara tujuan pendidikan damai, menurut Ian Harris, adalah:

to appreciate the richness of the concept of peace; to address fears; to provide information about security systems; to understand violent behaviour; to develop intercultural understanding; to provide for a future orientation; to teach peace as a process; to promote a concept of peace accompanied by social justice; to stimulate a respect for life; and to end violence. ${ }^{14}$

Menurut Elise Boulding, pendidikan damai yang terus menerus akan menghasilkan budaya damai. Budaya damai ini pertama-tama dapat ditemukan di dalam lingkup rumah tangga. Ia mengatakan bahwa, bahwa orang tua, khususnya para ibu memiliki peranan strategis dalam rangka mendidik dan menumbuhkan budaya damai dalam keluarga.

The familial household is an important source of peace culture in any society. It is there that women's nurturing culture flourishes. Traditionally, women have been the farmers as well as the bearers and rearers of children, the feeders and healers of the extended family. The kind of responsiveness to growing things-plants, animals, babies-that women have had to learn for the human species to survive is central to the development of peaceful behavior. ${ }^{15}$

Sebaliknya, keluarga dan rumah bisa menjadi sumber kekerasan dan pendidikan kekerasan bagi anggota-anggotanya. Penggunaan kekuasaan, khususnya dalam struktur keluarga yang patriarkis, terkadang menimbulkan kekerasan terhadap perempuan dan anak-anak. Anak-anak akan belajar dari orang tua mereka bagaimana menangani konflik, dan bagaimana mereka bersikap terhadap orang lain yang memiliki tampilan yang berbeda.

Untuk itu, pendidikan damai harus diperkenalkan semenjak dini kepada anak-anak, baik di lingkungan keluarga maupun di lingkungan sekolah melalui pendidikan formal dengan seperangkat kurikulum.

13 H.B. Danesh, "Towards an Integrative Theory of Peace Education," Journal of Peace Education, Vol. 3, No. 1, 2006, p. 56.

${ }^{14}$ Harris, I. (2002) “Conceptual Underpinnings of Peace Education," in: G. Salomon \& B. Nevo (Eds) Peace Education: The Concept, Principles, and Practices around The World, Lawrence Erlbaum, New York, p. 20

${ }^{15}$ Elise Boulding, "Peace Culture: The Problem of Managing Human Difference”. 
Para pendidik, termasuk para orang tua, para kiai maupun ustadz, yang mengajarkan pendidikan damai, menurut Canadian Centre for Teaching Peace hendaknya memiliki karakter sebagai berikut:

Peace educators establish democratic classrooms that teach cooperation and promote positive self esteem among their students. Teachers serve as peaceful role models to help to counteract images of violent behaviour young people receive through popular culture and in their homes. Their teaching style adjusts to the developmental needs of their pupils, respecting the various identities and concerns about violence students bring to the classroom. ${ }^{16}$

Menurut Ahmad Baedowi, untuk mengajarkan budaya damai di suatu lembaga pendidikan, seperti sekolah dan pondok pesantren, pihak manajemen sebaiknya mempertimbangkan untuk memasukkan agenda keragaman budaya dan etnik ke dalam kurikulum sekolah.

Selain kebutuhan instingtif siswa dalam memandang perbedaan, kebutuhan muatan budaya dan etnik dalam kurikulum formal juga akan meminimalisasi pemahaman siswa terhadap monopoli makna kebenaran secara sepihak. Selain itu, muatan keragaman budaya dan etnik dalam kurikulum pendidikan juga untuk mengubah dan menambah respons pedagogis guru atau ustadz dalam mengajar. Jika guru memiliki kepekaan budaya dan etnik yang kuat, respons pedagogis guru akan meningkat dengan sendirinya. Melalui pendekatan muatan kurikulum berbasis budaya, respons pedagogis para guru terhadap siswa juga akan berbeda. Hal tersebut dengan sendirinya akan membantu siswa dalam mengaksentuasi keragaman budaya di lingkungan mereka masing-masing. ${ }^{17}$

Geneva Gay dalam Culturally Responsive Teaching, sebagaimana dikutip Baedowi, memberikan sedikitnya lima argumen mengapa muatan budaya dan etnik itu sangat strategis dan penting untuk ditubuhkan dalam kurikulum pendidikan, termasuk pendidikan damai dan resolusi konflik. Pertama, muatan budaya dan etnik dalam kurikulum pendidikan sangat krusial sekaligus esensial bagi perbaikan aspek pedagogis pengajar dalam mengajar. Kedua, karena kebanyakan sumber belajar di ruang kelas adalah textbook, me-

16 Canadian Centre for Teaching Peace, "Peace Education Theory", artikel online: http://www.peace.ca/overview.htm, diunduh pada tanggal 9Desember 2010.

${ }^{17}$ Ahmad Baedowi, "Pendidikan Damai ...." 
masukkan agenda budaya dan etnik ke dalam textbook merupakan keniscayaan karena hal itu akan mengubah gaya mengajar guru. Ketiga, berdasarkan riset secara simultan di beberapa lembaga pendidikan, muatan budaya dan etnik dalam kurikulum pendidikan memiliki arti yang banyak bagi para siswa sekaligus meningkatkan apresiasi siswa dalam belajar. Keempat, relevansi muatan budaya dan etnik dalam kurikulum juga menyumbang kelestarian sejarah, budaya, dan tradisi sebuah etnis tertentu sehingga pada akhirnya dapat meningkatkan apresiasi kebangsaan yang tinggi dan memunculkan kohesivitas dan toleransi. Kelima, biasanya muatan budaya dan etnik diambil dari berbagai sumber yang sangat kaya, bukan hanya dari buku tetapi juga dari pengalaman orang perseorangan, baik melalui wawancara maupun yang didokumentasikan dalam bentuk tayangan dan sebagainya. Artinya, sumber informasi yang sangat melimpah tentang budaya dan etnis di luar sekolah itu akan membantu baik guru maupun siswa dalam menciptakan kecintaan terhadap keragaman pola kehidupan.

Menurut International Peace Research Association (IPRA), dalam konferensi yang ke-17 di Durban, Afrika Selatan, pada tanggal 23 Juni 1998, dinyatakan bahwa pendidikan damai adalah proses memberdayakan orang dengan kecakapan, sikap dan pengetahuan (skills, attitudes, and knowledge) untuk: (1) Membangun, memelihara dan memperbaiki hubungan di semua level dalam seluruh interaksi manusia (to build, maintain, and restore relationships at all levels of human interaction); (2) Mengembangkan pendekatan-pendekatan positif terhadap cara untuk menangani konflik, dari level personal sampai tingkat internasional; (3) Menciptakan lingkungan yang aman, baik lingkungan fisik maupun emosi yang mengayomi semua individu; (4) Menciptakan sebuah dunia yang aman berdasarkan keadilan dan hak asasi manusia; (5) Membangun sebuah lingkungan yang lestari dan menjaganya dari eksploitasi dan peperangan. ${ }^{18}$

Singkatnya, pendidikan damai adalah sebuah proses pendidikan yang didasari oleh filosofi yang mengajarkan nir kekerasan, cinta, kasih sayang, kepercayaan (trust), keadilan, kerjasama seluruh umat manusia.

18 IPRA, "Peace Education Theory," artikel online http://www.peace.ca/peaceeducationtheory.htm, diunduh pada tanggal 12 Desember 2010. 


\section{Pendidikan Damai di Pondok Pesantren Latansa}

\section{Sekilas Pondok Pesantren Latansa}

Pondok Pesantren Modern Latansa bertempat di desa Cangkring Kecamatan Karanganyar Kabupaten Demak. Pondok Pesantren Latansa ini menitikberatkan pada pengasuhan anak-anak bermasalah; seperti anak-anak korban konflik baik konflik personal keluarga (broken home) maupun konflik komunal, anak-anak korban bencana alam, anak-anak jalanan, dan anak-anak dari keluarga miskin absolut.

Pertama berdiri, yaitu di tahun 2000, Pondok Pesantren Latansa hanya memiliki tujuh santri yang kesemuanya adalah anak-anak yang putus sekolah dan memiliki masalah sosial. Ketujuh anak tersebut tinggal di rumah Bapak Masduki, ayahanda dari ustadz Ulinuha yang juga pengasuh pondok. Namun seiring dengan berjalannya waktu, santri berdatangan dari berbagai daerah sekitar Karanganyar seperti dari kudus, Pati, Jepara, bahkan ada yang berasal dari Tegal, Bandung, Madiun, Bengkulu, Maluku dan Papua yang saat ini jumlahnya tidak kurang dari enampuluh santri.

Di antara prestasi yang telah dicapai Pondok Pesantren Latansa, antara lain: Juara I Lomba Pidato Bahasa Arab. Remasade Festival Maulid XV Tahun 2001, Juara III Pidato Bahasa Inggris putri. Pospeda Provinsi Jawa tengah tahun 2005, Juara II Speech Contest Arabic MA, SMA se-Kabupaten Demak tahun 2005, Juara II Debate Contest Arabic, MA, SMA, se-Kabupaten Demak tahun 2005, Juara I Puisi Kategori Anak, Harlah Ponpes al-Muayyad XV tahun 2008, Juara II Puisi Kategori Anak, Harlah ponpes al-Muayyad XV tahun 2008, Juara II Pidato Bahasa Indonesia Kategori Anak, Harlah Ponpes al-Muayyad tahun 2008, Hari Anak Nasional, se-Kabupaten Demak tahun 2009, Juara I Pidato Bahasa Inggris, Festival Anak Sholeh TPQ se-Kabupaten Demak tahun 2008, Juara I Pidato Bahasa Arab Putri, Lomba Festival Anak Sholeh TPQ seKecamatan Karanganyar tahun 2009, Juara I Pidato Bahasa Inggris Putra, Festival Anak Sholeh TPQ se-Kecamatan Karanganyar tahun 2010, dan Juara I Pidato Bahasa Inggris Putri, Festival Anak Sholeh TPQ se-Kecamatan Karanganyar tahun 2010 .

\section{Pendidikan Damai di Ponpes Latansa}

Di antara aspek-aspek pendidikan damai yang bisa ditemukan dalam pendidikan santri di Pondok Pesantren latansa, antara adalah: 


\section{a. Pengelolaan Keragaman}

Sebagaimana disebutkan di muka bahwa pendidikan damai meniscayakan adanya pengelolaan keragaman, maka Pondok Pesantren Latansa mempertemukan para santri yang berasal dari area konflik, yaitu dari Papua dan Maluku, dengan para santri yang berasal dari daerah lainnya seperti Jawa Barat, Jawa Tengah dan jawa Timur. Mereka ditempatkan dalam kamar yang sama. Dalam pertemuan ini terjadi interaksi yang terkadang saling bergesekan satu sama lain. Namun sisi positifnya adalah mereka saling memahami. Hal ini didukung juga oleh nilai-nilai yang diajarkan oleh Pondok Pesantren, diantaranya adalah nilai yang menyatakan bahwa semua Muslim adalah saudara. Ustadz Ulinuha akhirnya mempersaudarakan mereka. Dalam hal ini ia mengambil inspirasi dari proses pembauran antara Muhajirin dan Anshar yang dilakukan oleh Rasulullah SAW, yaitu dengan cara dipersaudarakan. Sebuah teori mengatakan bahwa, konflik bisa terjadi karena adanya identitas yang terancam. Adanya usaha menumbuhkan empati dan rekonsiliasi di antara identitas yang beragam tersebut bisa mewujudkan perdamaian.

\section{b. Pembagian Uang Jatah Harian yang Adil}

Seluruh anak-anak korban konflik diberi jatah harian yang sama. Mereka mendapatkan makan tiga kali sehari dengan menu yang sama untuk semua anak. Di samping itu mereka diberi uang harian (uang 'jajan') sebesar Rp. 2000,- (dua ribu rupiah sehari). Keadilan memberikan sumber hidup anakanak ini juga merupakan suatu unsur pendidikan damai. Hal ini mengingat bahwa konflik terjadi bisa disebabkan oleh ketidakadilan dalam hal akses terhadap sumber-sumber ekonomi, atau tersumbatnya saluran manusia untuk memenuhi kebutuhan hidupnya (Human Needs Theory).

\section{c. Keadilan Gender}

Menurut Carolyn N. Stephenson, dalam Gender Equality and A Culture of Peace, perdamaian dan budaya damai akan susah diwujudkan jika tidak ada keadilan gender. Pondok pesantren Latansa telah menerapkan keadilan gender ini dalam hal pembagian peran antara santri laki-laki dan santri perempuan. Santri laki-laki memiliki tugas untuk berbelanja kebutuhan harian pondok termasuk kebutuhan bahan pokok makanan, sedangkan santri per- 
empuan bertugas untuk memasak keperluan makan santri, dan santri lakilaki yang bertugas untuk membersihkan peralatan memasak dan mencuci piring. Ustadz Ulinuha menentukan pembagian tugas ini melalui musyawarah yang dilakukan bersama para santrinya. ${ }^{19}$

\section{d. Pendidikan Kesabaran}

Pada awalnya, menurut santri yang berasal dari pulau Jawa, anak-anak dari Papua dan Maluku memiliki watak keras. Ketika tersinggung, kata-kata seperti "Aku bunuh kamu," terbiasa keluar. Ketika marah mereka juga langsung mengambil batu, mengancam untuk melempar siapa saja yang membuat mereka marah. Namun lambat-laun sifat seperti ini menghilang seiring dengan pendidikan yang diberikan oleh para ustadz dan ustadzah. Menurut Lusiyanti, mendidik anak-anak korban konflik memang membutuhkan kesabaran ekstra. Khususnya bagaiamana caranya agar mereka merasa di"uwongke" atau dihormati. Hal yang memberatkan lainnya adalah sikap beberapa masyarakat sekitar pondok, khususnya anak-anak muda yang ignorance, yang iseng memanggil mereka dengan sebutan 'ketek' (kera) karena tampilan mereka yang berkulit gelap dan berbeda dengan anak-anak di Demak pada umumnya. Sehingga disamping mendidik anak-anak tersebut, upaya lainnya yang dilakukan pondok adalah mendidik anak-anak untuk turut berempati terhadap mereka. Untuk membaangkitkan semangat anakanak, ustadz biasanya merujuk kepada ajaran Islam yang menyatakan bahwa yang paling mulia di sisi Allah adalah orang yang paling bertakwa, bukan berdasarkan keturunan dan bukan pula warna kulit.

\section{e. Pembauran dengan Warga Masyarakat}

Untuk menghilangkan stereotype para santri yang berasal dari Papua dan Maluku, maka mereka diajarkan untuk berbaur dengan masyarakat. Tidak jarang mereka diperbantukan untuk membantu masyarakat yang memiliki acara hajatan, mereka juga diperbantukan untuk melakukan kerja bakti bersama masyarakat sekitar, seperti pembuatan saluran air dan pengurukan jalan. Dengan cara ini, tidak sedikit masayarakat yang menaruh simpati dan

${ }^{19}$ Carolyn N. Stephenson, "Gender Equality and a Culture of Peace," in Joseph de Rivera, Handbook of Building Cultures of Peace, (New York: Springer, 2009), p. 123. 
menyisihkan sebagian rezeki mereka, baik berupa makanan maupun uang untuk disumbangkan kepada anak-anak korban konflik tersebut.

\section{f. Pedidikan Life Skills}

Ustadz Ulinuha menyadari bahwa anak-anak korban konflik ini tidak akan selamanya diurus oleh pondok, mereka harus bisa hidup mandiri di masa yang akan datang. Maka mereka juga diajari beberapa kecakapan yang membuat mereka siap untuk hidup mandiri. Dalam hal ini pondok pesantren bekerja sama dengan para ahli melalui Pemerintah Daerah Demak. Anakanak korban konflik ini, dan juga secara otomatis santri lainnya, diberi keahlian beternak kambing, bertani, perikanan, menjahit dan percetakan (sablon). Sebagaimana kedamaian positif membutuhkan berjalannya sistem kehidupan, seperti sistem ekonomi yang adil dan menyejahterakan, maka prasyarat-prasyarat untuk menuju ke arah itu mutlak dibutuhkan. Agar bisa hidup mandiri secara ekonomi, anak-anak perlu life skill yang mumpuni.

\section{Kesimpulan}

Dari hasil paparan singkat di atas, meskipun tidak secara eksplisit Pondok Pesantren Latansa melakukan pendidikan damai bagi santri-santrinya, khususnya bagi mereka yang berlatar belakang konflik, namun sistem yang diberlakukan dan kegiatan-kegiatan yang dijalankan di Pondok Pesantren Latansa memiliki beberapa unsur yang dapat ditemui dalam teoriteori pendidikan damai, seperti; pengelolaan keragaman, keadilan gender, pengelolaan emosi (kesabaran), dan yang lainnya. Sistem pendidikan yang di lakukan pondok tersebut juga bisa dikategorikan sebagai pendidikan karakter, yaitu karakter damai. Hal ini membuat para santri, khususnya yang berasal dari Papua dan Maluku bisa terbebas dari trauma, tidak membawa dendam dalam hidup, dan mampu menjadi manusia yang mencintai perdamaian.[w] 


\section{BIBLIOGRAFI}

Abdullah, "Pesantren dan Budaya Damai," artikel online http://desuga. mywapblog.com/, 23 Agustus 2009, diakses 28 September 2010.

Abu Bakar, Irfan, "Paradigma Peace-Building Pasca Konflik Kekerasan," artikel online http://www.csrc.or.id/artikel/, 27 Maret 2007, diakses 28 September 2010.

Baedowi, Ahmad, “Pendidikan Damai dan Resolusi Konflik untuk Sekolah,” koran Media Indonesia, Senin, 1 Maret 2010.

Bah-Date, Euginia, Jobs After War: A Critical Challenge in the Peace and Reconstruction Puzzle, Geneva: International Labour Office, 2003.

Bohm, RP. C.J. Fatlolon, Dkn Costan, Fr. Pr (ed.), Lintasan Peristiwa Kerusuhan Maluku tahun 1999-2002, Ambon: Keuskupan Amboina, 2002.

Canadian Centre for Teaching Peace, "Peace Education Theory," artikel online http://www.peace.ca/overview.htm, diunduh tanggal 9 Desember 2010.

Carolyne Ashton, Evaluation Report Program Pendidikan Damai Aceh, Jakarta: Unicef, 2002.

Coppel, Charles A., Vilonece Conflicts in Indonesia: Analysis, Representation, Resolution, New York: Routledge, 2006.

Danesh, H.B., "Towards an Integrative Theory of Peace Education," Journal of Peace Education, Vol. 3, No. 1, 2006.

Elizabeth F. Collins, “Indonesia: a Violent Culture?” Asian Survey, vol. 42/4, 2002.

Harris, Ian, "Conceptual underpinnings of peace education," in G. Salomon \& B. Nevo (eds) Peace Education: The Concept, Principles, and Practices around The World, New York: Lawrence Erlbaum, 2002.

Hefner, Robert W., "Muslim Democrats and Islamist Violence in Post-Soeharto Indonesia," in Robert W. Hefner (ed.), Remaking Muslim Politics: Pluralism, Contestation, Democratization, Princeton: Princeton University Press, 2005.

Jamil, M. Mukhsin, Mengelola Konflik Membangun Damai: Teori, Strategi dan Implementasi Resolusi Konflik, Semarang: Walisongo Mediation CentreNuffic, 2007. 
Malik, Ichsan, "Kedamaian, Keadilan, Hak Asasi \& Penegakan Hukum," bahan presentasi kuliah Pasca Sarjana IAIN Walisongo, Semarang, 27-28 Maret 2008.

Mayell, Hillary, "Refugee Children, Victims of War and Want, National Geographic," artikel online http://news.nationalgeographic.com/news/pf/ 30908037. html, June 19, 2003, diakses 28 September 2010.

Meirio, Akbar, "Penanganan Anak Korban Konflik," artikel online http://www. acehinstitute.org/, Rabu 12 Juni 2007, diakses 28 September 2010.

Musahadi HAM (ed.), Mediasi dan Resolusi Konflik di Indonesia: Dari Konflik Agama Hingga Mediasi Peradilan, Semarang: Walisongo Mediation CentreNuffic, 2007.

Nizar, M, "Memadamkan Dendam Anak-anak Korban Konflik di Aceh," dalam http://www.kabarindonesia.com/berita.php?pil=20\&dn=20080925144 603, 25 September 2008, diakses 28 September 2010.

Nizar, M, "Pendidikan Anak Korban Konflik," artikel online: http:// pendidikanlayanankhusus.wordpress.com, 13 Oktober 2008, diakses 28 September 2010.

Peart, Natalie, "Children of Conflict: The Real Victims," Digital Journal: A Global Citizen Journalism News Network, artikel online: http://www.digitaljournal. com/article/274537, June 21, 2009 (diakses 28 September 2010).

Simon Fisher etal, Mengelola Konflik Keterampilan dan Strategi Untuk Bertindak, terj.SN. Karikasari dkk, Jakarta: Gramedia, 2001.

Soedijar, Ahmad, ZA, Bencana Sosial Sampit, Jakarta: Balitbangsos Depsos RI, 2002.

Soetrisno, Loekman, Konflik Sosial: Studi Kasus Indonesia, Yogyakarta: Tajidu Press, 2003.

Syafuan Rozi, dkk, Kekerasan Komunal: Anatomi dan Resolusi Konflik di Indonesia, Yogyakarta: Pustaka Pelajar, 2006.

Wawancara dengan Fachruddin Zuhri, Ketua Ikatan Santri Latansa, pada tanggal 17 April 2011.

Wawancara dengan Fatah, usia 15 tahun, santri asal Papua, pada tanggal 20 Mei 2011.

Wawancara dengan Ali Wendi Jamurfui, 17 tahun, santri asal Maluku, pada tanggal 17 April 2011. 
Wawancara dengan Hidayat, 16 tahun, santri asal Papua, pada tanggal 20 Mei 2011.

Wawancara dengan Muhlis, usia tidak diketahui, santri asal Papua, pada tanggal 20 Mei 2011.

Wawancara dengan Ramli, 13 tahun, santri asal Papua, pada tanggal 20 Mei 2011.

Wawancara dengan Ridwan, 13 tahun, santri asal Demak, pada tanggal 20 Mei 2011.

Wawancara dengan Susmanto, santri senior Pondok Pesantren Latansa, Cangkring Karanganyar Demak, pada tanggal 20 Mei 2011.

Wawancara dengan Usman, unur tidak diketahui, santri asal Papua, pada tanggal 20 Mei 2011.

Wawancara dengan Ustadz Ali Mustawa, Bagian Pengasuhan Santri Pondok Pesantren Latansa, Cangkring Karanganyar Demak, pada tanggal 20 Mei 2011.

Wawancara dengan Ustadz Ulinuha Masduki, Pimpinan Pondok Pesantren Latansa, pada tanggal 20 Mei 2011. 